\title{
REPENSANDO O ANIMADO, REANIMANDO O PENSAMENTO ${ }^{1}$
}

\author{
TIM INGOLD ${ }^{2}$ \\ UNIVERSITY OF ABERDEEN
}

\begin{abstract}
RESUMO: $O$ animismo é frequentemente descrito como a atribuição de vida a objetos inertes. Essa atribuição é mais facilmente encontrada entre pessoas oriundas das sociedades ocidentais que sonham em encontrar vida em outros planetas do que entre povos indígenas a quem o rótulo de animistas foi tradicionalmente aplicado. Esses povos não estão unidos por suas crenças, mas na maneira de ser que está viva e aberta para um mundo em contínuo nascimento. Nessa ontologia anímica, os seres não se movem em um mundo já acabado, deslocam-se em um mundo em formação, de acordo com suas relações. Para seus habitantes, esse mundo-clima, abrangendo tanto o céu quanto a terra, é uma fonte de assombro, mas não de surpresa. A reanimação da tradição do pensamento 'ocidental' significa recuperar a capacidade de assombrar-se, banida da ciência oficial.
\end{abstract}

PALAVRAS-CHAVE: Animismo; ontologia relacional; movimento; mundo-clima; ciência.

ABSTRACT: Animism is often described as the imputation of life to inert objects. Such imputation is more typical of people in western societies who dream of finding life on other planets than of indigenous peoples to whom the label of animism has classically been applied. These peoples are united not in their beliefs but in a way of being that is alive and open to a world in continuous birth. In this animic ontology, beings do not propel themselves across a ready-made world but rather issue forth through a world-in-formation, along the lines of their relationships. To its inhabitants this weather-world, embracing both sky and earth, is a source of astonishment but not surprise. Re-animating the 'western' tradition of thought means recovering the sense of astonishment banished from offi cial science.

KEYWORDS: Animism; relational ontology; movement; weather-world; science.

\footnotetext{
${ }^{1}$ Traduzido por Paula Marcolin em 2010, a partir do original Rethinking the Animate, Re-Animating Thought, publicado em março de 2006 no periódico Ethnos (Routledge, vol. 7, n. 1, p. 9-20)@.

${ }^{2}$ University of Aberdeen, Escócia. E-mail: tim.ingold@abdn.ac.uk
}

Espaço Ameríndio, Porto Alegre, v. 7, n. 2, p. 10-25, jul./dez. 2013. 
Frequentemente, a mídia ocidental registra grande entusiasmo com a expectativa iminente de descobrir vida no planeta Marte. Essa expectativa é tão potente que os líderes mundiais - apesar do nível intelectual questionável - apostam sua reputação ao prometer que irão conseguir satisfazê-la. Os astrônomos capciosos, cercados pela falta crônica de recursos para seus projetos mais dispendiosos, estão bem conscientes da importância de manter a sensação de entusiasmo em ebulição. Enquanto os políticos veem nisso uma chance de garantir seu lugar na história, os astrônomos sabem que o dinheiro irá continuar entrando. Para o resto da população, talvez de maneira ingênua, porém menos cínica, a ideia de vida em outro planeta exerce um fascínio duradouro. A ideia também me fascina. Porém, estou longe de saber o que exatamente os cientistas esperam ou imaginam encontrar na superfície do planeta. Será vida o tipo de coisa que terá ficado na paisagem marciana? Se for esse o caso, como a reconheceríamos se a encontrássemos? Talvez, a resposta possa estar no fato que nós identificaríamos vida em Marte da mesma forma que identificaríamos vida no nosso próprio planeta. Porém, não estou muito certo de como faríamos isso. O que eu tenho certeza, uma vez que nós sabemos disso pela etnografia, é que as pessoas nem sempre concordam sobre o que está vivo e o que não está; e até mesmo quando elas concordam, isso pode ocorrer, muitas vezes, por razões completamente diferentes. Também estou certo de que, porque nós também sabemos disso pela etnografia, nem todas as pessoas discriminam de modo universal entre as categorias de coisas com e sem vida. Isso acontece porque, para muitas pessoas, a vida não é, de forma alguma, um atributo das coisas. Ou seja, ela não emana de um mundo que já existe, povoado por objetos, ao invés disso, é imanente ao próprio processo de geração contínua ou do vir-a-ser do mundo.

As pessoas que têm essa compreensão da vida - e entre elas estão muitas com quem os antropólogos trabalham em regiões tão diversas como a Amazônia, o Sudeste Asiático e o Norte Circumpolar são frequentemente descritas na literatura como animistas. De acordo com uma convenção há muito estabelecida, o animismo é um sistema de crenças que atribui vida ou espírito a coisas que são de fato inertes. Mas essa convenção, como irei demonstrar, é equivocada por duas 
razões. Primeiramente, não estamos lidando com uma crença sobre o mundo, mas com uma condição de ser no mundo. Isso poderia ser descrito como uma condição de estar vivo para o mundo, caracterizado por uma capacidade elevada de sentir e responder, na percepção e na ação, a um ambiente que está sempre em fluxo, que não permanece $o$ mesmo de um momento para o outro. A animização, então, não é a projeção imaginativa de propriedades humanas nas coisas que elas percebem ao seu redor. Ao contrário, e esse é o meu segundo ponto, a animização é o potencial dinâmico e transformativo de todo um campo de relações dentro do qual os seres de todos os tipos, mais ou menos pessoa ou coisa, geram a existência um do outro de forma contínua e recíproca. A animização do mundo vivo, em suma, não é resultado de uma infusão de espírito na substância, ou de ação à materialidade, mas é ontologicamente anterior a essa diferenciação.

Certamente, não sou o primeiro a observar que os verdadeiros animistas, de acordo com a definição convencional do termo, são, precisamente, aqueles que sonham em encontrar vida em Marte. Eles realmente acreditam que há um princípio vital que anima e que pode estar alojado no interior de objetos físicos, fazendo-os ir e se multiplicar. Essa era a mesma crença que os etnólogos do século XIX projetaram nos selvagens que conheciam, acusando-os, por sua vez, de aplicar o pensamento de uma maneira liberal demais, de modo a incluir tudo, vivo ou não. Não devemos, portanto, nos surpreender com o paralelo entre os astrônomos do início do século XXI, que esperam descobrir vida oculta nas matérias de outros planetas, e seus antecessores etnólogos que se propuseram a descobrir crenças animistas ocultas no pensamento de outras culturas. Os psicólogos sugerem que essas crenças estão estabelecidas na base de uma predisposição inconsciente que mesmo "adultos educados" compartilham com as crianças e os povos supostamente primitivos uma predisposição de agir como se os objetos inanimados estivessem realmente vivos (BROWN e THOULESS, 1965). O argumento é que, se você não sabe se alguma coisa está viva ou não, é melhor apostar que está e se precaver. Os custos do erro, em alguns casos, ultrapassam os benefícios do acerto em outros (GUTHRIE, 1993, p. 41). Portanto, todos nos tornamos animistas enrustidos sem, obviamente, ter percebido. Os 
TIM INGOLD - Repensando o animado, reanimando o pensamento

não animistas intuitivos foram eliminados por seleção natural devido aos encontros desafortunados com coisas que acabaram sendo mais vivas que o esperado.

\section{Nascimento contínuo}

Absurdos à parte, argumentos como esse seguem a mesma lógica. Chamo-a de lógica da inversão, e ela está profundamente sedimentada no pensamento dos cânones ocidentais (INGOLD, 1993, p. 218-219). Através da inversão, o campo de envolvimento no mundo, de uma coisa ou de uma pessoa, é convertido em um esquema interior cuja aparência ou comportamento manifesto são expressões exteriores. Assim o organismo, que se move e cresce ao longo das linhas que o unem à teia da vida, é reconfigurado como uma expressão exterior de um desenho interno. Convencionalmente identificados como genótipo, considera-se que esse desenho constitua a base da forma manifesta do fenótipo. Da mesma forma, presume-se que uma pessoa, ao agir e perceber o mundo dentro de um nexo de relações interconectadas, aja de acordo com as indicações dos modelos culturais ou esquemas cognitivos instalados dentro de sua cabeça. Através da inversão, os seres originalmente abertos para o mundo se fecham em si mesmos, fechados por uma fronteira ou casca externa que protege a sua constituição interna do tráfego de interações com o ambiente que os cerca. Meu objetivo é reverter essa lógica. Considerando que a vida foi virada, por assim dizer, 'de fora para dentro', eu quero agora virá-la de dentro para fora novamente, a fim de recuperar a abertura original para o mundo em que as pessoas que nós (isto é, etnólogos treinados no ocidente) chamamos de animistas encontram o sentido da vida.

Um homem entre os Wemindji Cree, caçadores nativos do norte do Canadá, ofereceu o seguinte significado para o etnógrafo Colin Scott. A vida, disse ele, é "nascimento contínuo" (SCOTT, 1989, p. 195). Eu quero pregar isso na minha porta! Isso vai ao cerne da questão. Elaborando: a vida na ontologia anímica não é uma emanação, mas uma geração de ser, num mundo que não é pré-ordenado, mas incipiente, sempre à beira do real (INGOLD, 2000, p. 113). Alguém está 
continuamente presente como testemunha desse momento, sempre em movimento, como a crista de uma onda, na qual o mundo está prestes a revelar-se como ele é. Em seu ensaio Eye and Mind, Maurice MerleauPonty (1964) atribuiu precisamente o mesmo tipo de sensibilidade - a mesma abertura para um mundo em formação - para o pintor. A relação do pintor com o mundo, escreve Merleau-Ponty, não é simplesmente "físico-ótica". Ou seja, ele não contempla um mundo que é finito e completo, e se propõe a criar uma representação dele. Ao invés disso, a relação é de um "nascimento continuo" - essas são as palavras de Merleau-Ponty - como se a cada momento o pintor abrisse os olhos para o mundo pela primeira vez. Sua visão não é das coisas no mundo, mas as coisas se tornando coisas, e do mundo se tornando um mundo (MERLEAU-PONTY, 1964, p. 167-168, 181). O pintor Paul Klee expressou essa mesma ideia em seu Creative Credo de 1920. A arte, ele declarou em uma famosa frase, "não reproduz o visível, mas torna visível" (KLEE, 1961, p. 76).

\section{A constituição relacional do ser}

Quero destacar dois pontos sobre essa percepção anímica do mundo. Um deles diz respeito à constituição relacional do ser, o outro diz respeito à primazia do movimento. Vou lidar com um de cada vez. $\mathrm{O}$ primeiro ponto me leva de volta à lógica da inversão. Vamos imaginar um organismo ou uma pessoa. Eu poderia representá-lo assim:

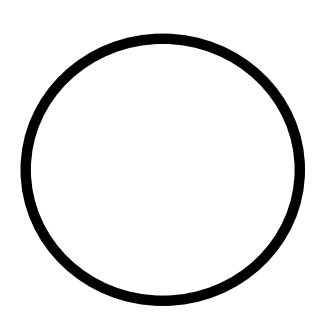

Porém, nessa representação aparentemente inocente, eu já realizei uma inversão. Eu fechei o organismo em si mesmo de tal forma que ele está delineado e contido dentro de um perímetro que estabelece uma 
fronteira, separado de um mundo circundante - um ambiente - com o qual é destinado a interagir de acordo com sua natureza. O organismo está "aqui dentro", e o ambiente "lá fora". Mas em vez de desenhar um círculo, eu poderia muito bem ter desenhado uma linha. Então, vamos começar de novo. Eis um organismo:

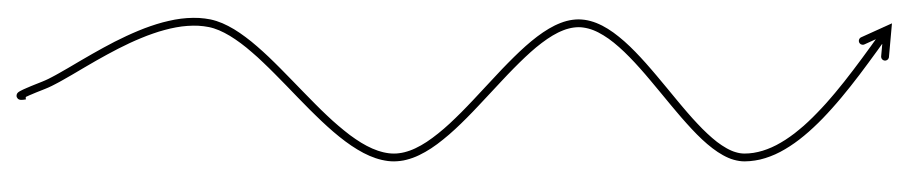

Nessa representação não há dentro ou fora, e nenhum limite que separe os dois domínios. Pelo contrário, há uma trilha marcando um movimento ou crescimento. Cada trilha traça uma relação. Mas a relação não está entre uma coisa e outra - entre o organismo 'aqui' e o ambiente 'lá'. Ao contrário, é uma trilha ao longo da qual a vida é vivida: um fio em um tecido de trilhas, que formam a textura do mundo da vida. É essa a textura a que me refiro quando falo de organismos que estão sendo constituídos dentro de um campo relacional. Não é um campo de pontos interconectados, mas de linhas entrelaçadas, não uma rede mas uma teia.

No entanto, a representação de uma única linha é obviamente uma simplificação. Pois a vida dos organismos geralmente não se estende ao longo de uma, mas várias trilhas, brotando de uma única fonte. Devemos imaginar o organismo, então, não como um objeto autocontido, como uma bola que pode se movimentar de um lugar para outro, mas como uma rede cada vez mais ramificada de linhas do crescimento. Os filósofos Gilles Deleuze e Félix Guattari (1983) celebremente compararam esta rede a um rizoma, embora eu prefira a imagem do micélio fúngico (INGOLD, 2003, p. 302-306). Qualquer que seja a metáfora que nós escolhermos, o organismo agora se parece com algo desse tipo: 


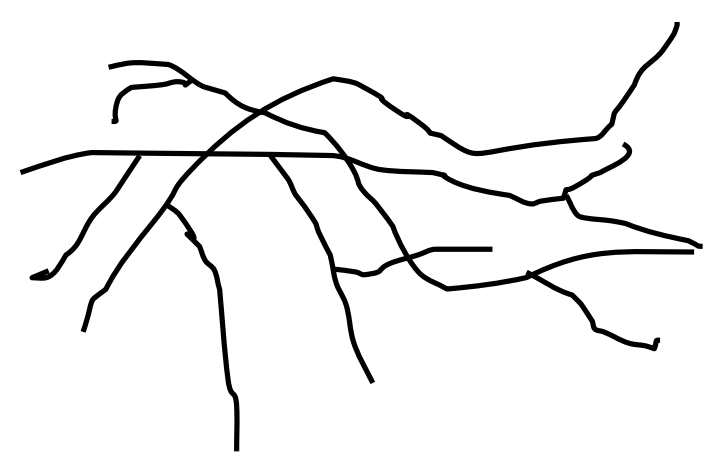

É desnecessário dizer que esta representação também seria adequada para pessoas que, sendo organismos, se estendem da mesma forma pelos diversos caminhos de seu envolvimento no mundo.

Mas, agora, o que aconteceu com o ambiente? Não pode ser o que literalmente circunda o organismo ou a pessoa, uma vez que você não pode circundar uma rede sem traçar uma linha em torno dela. E isso imediatamente resultaria em uma inversão, convertendo aquelas relações ao longo das quais a pessoa-organismo vive sua vida no mundo em propriedades internas das quais sua vida não seria senão a expressão exterior. Podemos imaginar, no entanto, que as linhas do crescimento emitidas de várias fontes se tornam plenamente entrelaçadas umas com as outras, mais ou menos como as vinhas e cipós de uma mata cerrada da floresta tropical ou o sistema de raízes emaranhadas que você corta com a pá cada vez que você cava o jardim. O que estamos acostumados a chamar de "ambiente" pode, então, ser melhor visualizado como um domínio de emaranhamento. É dentro desse emaranhado de trilhas entrelaçadas, continuamente enredandose aqui e desenredando-se lá, que os seres crescem ou "seguem adiante" ao longo das linhas de suas relações (INGOLD, 2003, p. 305306).

Esse emaranhado é a textura do mundo. Na ontologia anímica, os seres não ocupam simplesmente o mundo, eles o habitam e, ao fazê-lo - ao percorrer seus próprios caminhos através da teia -, eles contribuem para manter a trama sempre em evolução. Portanto, devemos parar de nos referir ao mundo como um substrato inerte, sobre a qual as coisas vivas se movem como as peças de um tabuleiro ou atores em um palco, onde os artefatos e a paisagem substituem, respectivamente, as 
propriedades e o cenário. Pela mesma razão, os seres que habitam o mundo (ou que são verdadeiramente indígenas neste sentido) não são objetos que se movem, sofrendo deslocamentos de um canto a outro na superfície do mundo. Na verdade, o mundo habitado como tal não tem superfície. Qualquer superfície que encontrarmos, seja ela do solo, da água, da vegetação ou dos edifícios estão no mundo, não são do mundo (INGOLD, 2000, p. 241). E entrelaçados em sua própria textura estão as linhas de crescimento e movimento de seus habitantes. Cada linha, em suma, é um caminho ao longo, ao contrário de um caminho através. E é como linhas de movimento, e não como entidades móveis autopropulsoras, que os seres são instanciados no mundo. Isso me leva ao meu segundo ponto, sobre a primazia do movimento.

\section{A primazia do movimento}

O mundo anímico está em fluxo perpétuo, na medida em que os seres que participam dele seguem seus diferentes caminhos. Esses seres não existem em locais fixos, eles se apresentam ao longo de caminhos. Entre os Inuit do Ártico canadense, por exemplo, como o escritor Rudy Wiebe mostrou (1989, p. 15), assim que uma pessoa se move ela se torna uma linha. As pessoas são conhecidas e reconhecidas pelos rastros que elas deixam pra trás. Os animais, da mesma forma, são reconhecidos por padrões característicos de marcas de atividade ou de movimento, e perceber um animal é testemunhar esta atividade em curso, ou ouvi-la. Assim, para tomar dois exemplos do maravilhoso relato de Richard Nelson da tribo Koyukon do Alasca, Make Prayers to the Raven, você vê "rasgando como um clarão de fogo através da vegetação", não uma raposa; e "se empoleirando nos galhos mais baixos de abetos", não uma coruja (NELSON, 1983, p. 108, 158). Os nomes dos animais não são substantivos, mas verbos.

Mas isso não é diferente dos corpos celestes, como o sol e a lua. Poderíamos pensar no sol como um disco gigante que é observado por fazer o seu caminho de leste a oeste através da grande abóboda do céu. Isso poderia ser representado assim: 


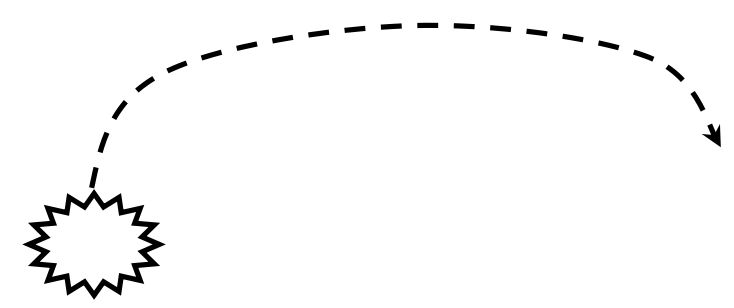

Mas nas inscrições pictográficas dos povos nativos das Planícies da América do Norte, essa representação é feita assim:

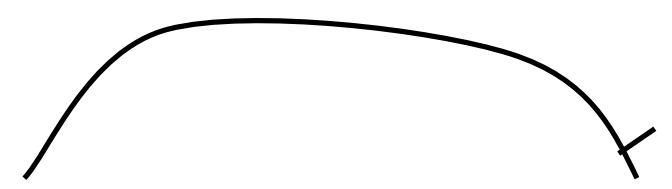

Ou assim:

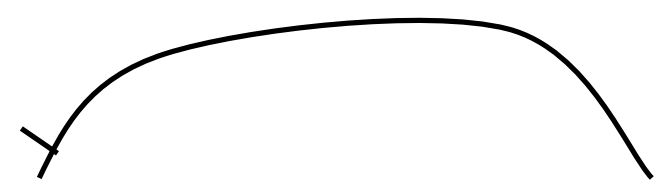

Onde o pequeno traço no final da linha indica o nascer ou o pôr do sol (FARNELL, 1994, p. 959). Nessas representações, o sol não é entendido como um objeto que se move através do céu. Pelo contrário, é identificado como um caminho de seu movimento ao longo do céu, em sua jornada diária do horizonte oriental para o ocidental. A maneira como devemos imaginar o céu, e em particular a relação entre o céu e a terra, é um problema para o qual voltarei mais tarde.

Onde há vida, há movimento. Nem todos os movimentos, no entanto, sinalizam vida. O movimento da vida é especificamente tornarse, ao contrário de estar, é de renovação ao longo de um caminho ao invés de deslocamento no espaço. Cada criatura, à medida que 'brota' e deixa rastros, se move de uma maneira característica. $O$ sol está vivo 
por causa da maneira como ele se move através do firmamento, e da mesma forma também as árvores estão vivas, por causa da forma peculiar que seus galhos balançam ou suas folhas sacodem ao vento, e por causa dos sons que elas produzem ao fazer isso. É claro que o cientista ocidental concordaria que a árvore está viva, embora ele possa ter dúvidas sobre o sol. Mas seus motivos seriam bastante diferentes. A árvore está viva, ele diria, não por causa de seu movimento, mas porque é um organismo celular, cujo crescimento é alimentado por reações de fotossíntese e regulado pelo DNA no núcleo da célula. Quanto a seus movimentos, eles são apenas efeito do vento. Mas o que dizer do vento? Novamente, o cientista teria suas próprias explicações: o vento é causado por diferenças horizontais e verticais na pressão do ar atmosférico. Isso também é um efeito. Na maior parte das cosmologias anímicas, no entanto, os ventos são considerados vivos e apresentam poderes agentivos próprios; em muitas cosmologias eles são pessoas importantes que dão forma e direção ao mundo em que as pessoas vivem, assim como fazem o sol, a lua e as estrelas.

Uma vez reconhecida a primazia do movimento no cosmos anímico, a inclusão no panteão de seres que a ciência moderna classificaria como fenômenos meteorológicos - não só os ventos, mas geralmente também o trovão - se torna facilmente compreensível. Não somos obrigados a acreditar que o vento é um ser que sopra, ou que o trovão é um ser que faz estrondos. Pelo contrário, o vento está soprando, e o trovão está fazendo estrondos, assim como os organismos e as pessoas estão vivendo de acordo com as maneiras peculiares de cada um. Mas eu acho que há um pouco mais a ser dito sobre a importância atribuída a essas manifestações do ser relacionadas ao clima, e isso me traz de volta à relação entre a terra e o céu.

\section{O Céu, a Terra e o Clima}

Mencionei anteriormente nossa propensão a supor que o mundo inanimado é apresentado para a vida como uma superfície a ser ocupada. A vida, dizemos, é vivida no chão, ancorada a alicerces sólidos, enquanto o clima gira acima de nossa cabeça. Abaixo desta 
TIM INGOLD - Repensando o animado, reanimando o pensamento

superfície encontra-se a terra, e acima dela, a atmosfera. Como substância sólida, a terra fornece suporte para atividades da vida e materiais para subsistência; como meio gasoso, o ar proporciona mobilidade e percepção sensorial, e, é claro, permite que os animais terrestres respirem (GIBSON, 1979, p. 16-22). Nos pronunciamentos de muitos teóricos, no entanto, o chão age como uma interface não só entre meio e a substância, mas mais fundamentalmente entre os domínios da agência e da materialidade. E isto tem uma consequência muito peculiar de tornar imaterial o meio através da qual os organismos e as pessoas se movem na realização de suas atividades. O que acontece, então, ao vento e à chuva, aos raios de sol e às nuvens, a geada e à neve que cai, aos trovões e relâmpagos?

A equação da materialidade com a substância sólida da terra cria a impressão de que a vida acontece sobre a superfície exterior de um mundo que já congelou em sua forma final, ao invés de um mundo em fluxo perpétuo. Entre a mente e a natureza, as pessoas e as coisas, e a agência e a materialidade, não há espaço conceitual para aqueles fenômenos e transformações muito reais do meio que geralmente chamamos de clima. Isso explica a ausência praticamente total do clima nos debates filosóficos sobre esses assuntos. É um resultado da lógica da inversão - uma lógica que coloca a ocupação antes da habitação, o movimento pelo antes do movimento através, a superfície antes do meio. Em termos dessa lógica, o clima é simplesmente impensável. $\mathrm{Na}$ ontologia anímica, pelo contrário, o que é inconcebível é a ideia de que a vida acontece sobre uma superfície inanimada de um mundo pronto. Visto que os seres vivos, de acordo com esta ontologia, fazem o seu caminho através de um mundo em nascimento, ao invés de ao longo da superfície pré-formada; as propriedades do meio através do qual eles se movem são de todo importante. É por isso que o mundo habitado é constituído, em primeiro lugar, pelo fluxo aéreo do clima, em vez de elementos fixos e ancorados na paisagem. O clima é dinâmico, sempre se desdobrando, sempre mudando o estado, as correntes, as qualidades de luz e sombra, cores, alternando entre úmido ou seco, quente ou frio, e assim por diante. Nesse mundo, a terra, longe de fornecer uma base sólida para a existência, parece flutuar como uma balsa frágil e efêmera, tecida a partir dos fios da vida terrestre e suspensa na grande esfera do 
céu. Essa esfera é o lugar onde está toda a ação sublime: onde o sol brilha, os ventos sopram, a neve cai, e a tempestade eclode. Trata-se de uma esfera em que pessoas poderosas não procuram estampar suas vontades sobre a terra, mas lançar voo com os pássaros, plainar com o vento, e conversar com as estrelas. Suas ambições, poderíamos dizer, são mais celestiais do que territoriais.

Este é o ponto para voltar à pergunta que fiz um momento atrás, do significado do céu e de sua relação com a terra. Considere a definição oferecida pelo dicionário Chambers. O céu, o dicionário nos informa, é "a abóboda aparente sobre as nossas cabeças". Isto é revelador em dois aspectos. Em primeiro lugar, o céu é imaginado como uma superfície, tal como a superfície da terra, exceto, naturalmente, por ser uma cobertura sobre as nossas cabeças, em vez de uma plataforma sob nossos pés. Em segundo lugar, ao contrário da superfície da terra, a do céu não é real, mas apenas aparente. Na realidade, não há absolutamente nenhuma superfície. Concebido como tal, o céu é um fantasma. É onde os anjos pisam. Seguindo o que já é uma linha de pensamento familiar, a superfície da terra tornou-se uma interface entre o concreto e o imaginário. $O$ que está abaixo (a terra) pertence ao mundo físico, enquanto que a curvatura acima (o céu) é sublimada em pensamento. Com os pés no chão e a cabeça no ar, os seres humanos parecem estar divididos na sua constituição entre o material e o mental. Dentro do universo anímico, no entanto, o céu não é uma superfície, real ou imaginária, mas um meio. Além disso, este meio, como vimos, é habitado por uma variedade de seres, incluindo o sol e a lua, os ventos, os trovões, os pássaros, e assim por diante. Esses seres deixam seus próprios rastros através do céu, assim como os seres terrestres deixam seus rastros através da terra. O exemplo da trajetória do sol já foi mencionado. Mas também se concebe que os ventos façam trilhas através do céu, vindo dos recantos que habitam (FARNELL, 1994, p. 943). A terra e o céu não são domínios mutuamente exclusivos de habitação. Os pássaros habitualmente se deslocam de um domínio para outro, como fazem humanos poderosos como os xamãs. Os esquimós Yup'ik, de acordo com Anne-Fienup Riordan (1994, p. 80), reconhecem uma classe de pessoas extraordinárias que são tão ágeis que elas 
TIM INGOLD - Repensando o animado, reanimando o pensamento

podem literalmente decolar, deixando um rastro de neve soprada pelo vento nas árvores.

\section{Assombro e Surpresa}

Em suma, longe de ficarem de frente um para o outro em ambos os lados de uma impenetrável divisão entre a o real e o imaterial, a terra e o céu estão inextricavelmente ligados dentro de um campo indivisível, integrados ao longo das emaranhadas linhas da vida de seus habitantes. Os pintores sabem disso. Eles sabem que pintar o que se convencionou chamar de 'paisagem' significa pintar a terra e o céu, e que a terra e o céu se misturam na percepção de um mundo em contínuo nascimento. Eles sabem também que a percepção visual desse céu-terra, ao invés de ser a de objetos na paisagem, é em primeiro lugar uma experiência de luz. Nas suas pinturas, eles têm como objetivo recuperar, por detrás da normalidade mundana da capacidade de ver coisas, o assombro absoluto daquela experiência, isto é, da capacidade de ver. Isto é o que Merleau-Ponty (1964, p. 166) chama de magia ou o delírio da visão. O assombro, creio eu, é o outro lado da moeda da própria abertura para o mundo que eu mostro ser fundamental para o modo anímico de ser. É o sentimento de admiração que surge quando navegamos na crista da onda do contínuo nascimento do mundo. No entanto, com a abertura vem a vulnerabilidade. Para as pessoas que não estão familiarizadas com essa forma de ser, parece frequentemente que se trata de timidez ou fraqueza, prova da falta de rigor característico das crenças e práticas supostamente primitivas. A maneira de conhecer o mundo, dizem, não é abrir-se para ele, mas sim "apreendê-lo" dentro de uma rede de conceitos e categorias. O assombro foi banido dos protocolos de investigações racionais conceitualmente induzidas. $\mathrm{O}$ assombro está em contraposição à ciência.

Ao buscar pelo fechamento ao invés da abertura, os cientistas ficam muitas vezes surpreendidos com o que eles acham, mas nunca assombrados. Os cientistas ficam surpresos quando suas predições se mostram erradas. O grande objetivo da predição, entretanto, repousa sobre a ideia de que o mundo pode ser responsabilizado. Mas é claro 
que o mundo segue seu próprio caminho de forma independente. O que o designer Stanley Brand diz sobre as construções arquitetônicas se aplica igualmente às construções da ciência: "Todas as construções são predições; todas as predições estão erradas" (1994, p. 178). Seguindo o programa popperiano de conjectura e refutação, a ciência transformou a surpresa em um princípio de avanço criativo, convertendo o seu registro acumulado de previsões erradas em uma história de progresso. A surpresa, porém, existe apenas para aqueles que esqueceram como ficar assombrados com o nascimento do mundo, que cresceram tão acostumados com o controle e com a previsibilidade que eles dependem do inesperado para assegurar-lhes que os eventos estão ocorrendo e que a história está sendo feita. Em contrapartida, aqueles que estão verdadeiramente abertos ao mundo, apesar de eternamente assombrados, nunca são surpreendidos. Se essa atitude de assombro não surpresa os deixa vulneráveis, ela também é uma fonte de força, resiliência e sabedoria. Pois ao invés de esperar o inesperado ocorrer e ser pego de surpresa em consequência, essa atitude permite que a cada momento eles respondam ao fluxo do mundo com cautela, discernimento e sensibilidade.

O animismo e a ciência são, portanto, irreconciliáveis? Uma abertura animista para o mundo seria inimiga da ciência? Certamente não. Não quero que minhas observações sejam interpretadas como um ataque a todo empreendimento científico. Mas a ciência, tal como é atualmente, repousa sobre um fundamento impossível, pois para transformar o mundo em um objeto de preocupação, ela tem que se colocar acima e além do mundo que ela pretende compreender. As condições que permitem os cientistas saberem, ao menos de acordo com protocolos oficiais, são tais que tornam impossível para os cientistas o estar no mundo sobre o qual eles buscam conhecimento. No entanto, toda ciência depende de observação, e toda observação depende de participação - isto é, uma união estreita, em percepção e ação, entre o observador e os aspectos do mundo que são o foco da sua atenção. Se a ciência pretende ser coerente em sua prática de conhecimento, ela deve ser reconstruída sobre as bases da abertura ao invés do fechamento, do engajamento ao invés da separação. E isso significa recuperar o senso de assombro que é tão notável por sua 
ausência no trabalho científico contemporâneo. O saber deve ser reconectado com o ser, a epistemologia com a ontologia, o pensamento com a vida. Assim, a nossa reavaliação do animismo indígena nos leva a propor a reanimação da nossa própria tradição de pensamento chamado 'ocidental'.

\section{Referências bibliográficas}

BRAND, Stanley. How Buildings Learn: What Happens To Them After They're Built. Harmondsworth: Penguin, 1994.

BROWN, L. B.; THOULESS, R. H. Animistic Thought in Civilized Adults. The Journal of Genetic Psychology, v. 6, n. 1, p. 33-42, 1965.

DELEUZE, Gilles; GUATTARI, Félix. On the Line. New York: Semiotext(e), 1983.

FARNELL, Brenda M. Ethno-graphics and the Moving Body. Man (N. S.), v. 29, n. 4, p. 929-974, 1994.

FIENUP-RIORDAN, Anne. Boundaries and Passages: Rule and Ritual in Yup'ik Eskimo Oral Tradition. Norman: University of Oklahoma Press, 1994.

GIBSON, James J. The Ecological Approach to Visual Perception. Boston: Houghton Mifflin, 1979.

GUTHRIE, Stewart E. Faces in the Clouds: A New Theory of Religion. Oxford: Oxford University Press, 1993.

INGOLD, Tim. The Art of Translation in a Continuous World. In: PÁLSSON, Gísli (Org.). Beyond Boundaries: Understanding, Translation and Anthropological Discourse. Oxford: Berg, 1993. p. 210-230.

The Perception of the Environment: Essays in Livelihood, Dwelling and Skill. Londres: Routledge, 2000.

Two Reflections on Ecological Knowledge. In: SANGA, Glauco; ORTALLI, Gherardo (Org.). Nature Knowledge: Ethnoscience, Cognition and Utility. New York: Berghahn, 2003. p. 301-311.

KLEE, Paul. Notebooks 1: The Thinking Eye. Londres: Lund Humphries, 1961. 
MERLEAU-PONTY, Maurice. Eye and Mind. In: EDIE, James M. (Org.). The Primacy of Perception: And other Essays on Phenomenological Psychology, the Philosophy of Art, History and Politics. Evanston: Northwestern University Press, 1964. p. 159-190.

NELSON, Richard K. Make Prayers to the Raven: A Koyukon View of the Northern Forest. Chicago: University of Chicago Press, 1983.

SCOTT, Colin. Knowledge Construction among Cree Hunters: Metaphors and Literal Understanding. Journal de la Société des Américanistes, Paris, v. 75, p. 193-208, 1989.

WIEBE, Rudy. Playing Dead: A Contemplation Concerning the Arctic. Edmonton, Canada: NeWest, 1989. 